\title{
Diferentes formas de aplicação da semente de Moringa oleifera no tratamento de água
}

Camila C. Arantes ${ }^{1}$, José E. S. Paterniani ${ }^{2}$, Danielle S. Rodrigues ${ }^{3}$, Patrícia S. Hatori ${ }^{4} \&$ Marta S. G. Pires $^{5}$

\section{Palavras-chave:}

saneamento rural coagulante natural filtração lenta

\begin{abstract}
R E S U M O
Coagulantes naturais e sistemas de filtração são tecnologias de tratamento de água, indicadas para comunidades rurais ou isoladas. Este estudo objetivou comparar duas formas de aplicação de coagulante extraído de sementes de Moringa oleifera. Utilizaramse o coagulante líquido ( $10 \mathrm{~mL} \mathrm{~L}^{-1}$ a $\left.20 \mathrm{~g} \mathrm{~L}^{-1}\right)$ e sachê contendo $0,8 \mathrm{~g}$ de pó de sementes de Moringa oleifera. Após as etapas de dispersão da proteína presente nas sementes de Moringa oleifera, coagulação e floculação efetuaram-se pré-filtração ascendente e filtração lenta. Diferenças significativas foram observadas entre o uso do coagulante líquido e sachê na redução de turbidez e cor aparente. Com o uso dos sachês o pré-filtro foi menos eficiente notando-se reduções médias de turbidez igual 73 e $83 \%$ para os sachês e coagulante líquido, respectivamente. No filtro lento verificou-se redução média de 84 e $60 \%$ com o uso de sachês e coagulante líquido, respectivamente. Considerando todo o sistema de filtração, o uso dos sachês resultou em elevados percentuais de redução de turbidez e cor aparente; além de que seu preparo não requer o uso de água, condição que favorece sua aplicação em regiões em que há escassez de água com qualidade.
\end{abstract}

\section{Key words:}

rural sanitation

natural coagulant

slow sand filtration

\section{Different forms of application of Moringa oleifera seeds in water treatment}

\begin{abstract}
A B S T R A C T
Natural coagulants and filtration systems are suitable water treatment technologies in rural or isolated communities. This research aimed to compare two forms of application of coagulant extracted from Moringa oleifera seeds. Coagulant liquid (10 $\mathrm{mL} \mathrm{L}^{-1}$ at $\left.2 \%\right)$ and pouches containing $0.8 \mathrm{~g}$ powder were used. The dispersion, coagulation and flocculation steps were performed prior to both up flow gravel pre-filtration and slow sand filtration. Significant differences were observed for the liquid coagulant and pouches regarding the reduction of turbidity and apparent color. Although the up flow gravel pre-filter was less effective with the use of pouches, with an average reduction of turbidity of 73.5 and $82.5 \%$ for the pouches and liquid coagulant, respectively, the effluent of the slow filter presented lower turbidity, with an average reduction of 83.9 and $60.1 \%$ for the pouches and liquid coagulant, respectively. Considering the filtration system (up flow gravel pre-filter and slow sand filter) the use of pouches showed high reduction of turbidity and apparent color. The preparation of pouches does not require the use of water, a condition that favors its application in areas with lack of water of acceptable quality.
\end{abstract}

Protocolo 047-2014 - 13/02/2014 • Aprovado em 07/11/2014 • Publicado em 26/01/2015

${ }^{1}$ FEC/UNICAMP. Campinas, SP. E-mail: kamilarantes@yahoo.com.br (Autora correspondente)

${ }^{2}$ FEAGRI/UNICAMP. Campinas, SP. E-mail: pater@feagri.unicamp.br

${ }^{3}$ FEAGRI/UNICAMP. Campinas, SP. E-mail: danielle.srodrigues@gmail.com

${ }^{4}$ FT/UNICAMP. Limeira, SP. E-mail: hatori.paty@gmail.com

${ }^{5}$ FT/UNICAMP. Limeira, SP. E-mail: marta@ft.unicamp.br 


\section{INTRODUÇÃO}

Os dados do censo demográfico de 2010 realizado pelo Instituto Brasileiro de Geografia e Estatística (IBGE, 2010), apontam que somente $27,8 \%$ da população rural do Brasil têm acesso à rede geral de abastecimento de água.

Comunidades rurais apresentam características peculiares que influenciam diretamente na implantação de serviços de saneamento. Para Nascimento \& Heller (2005), a dispersão e a baixa densidade populacional são os principais fatores que dificultam a implantação de ações de saneamento na zona rural. Tais autores consideram que a apropriação da tecnologia pela população é uma das problemáticas em tais situações.

Tecnologias de tratamento de água para comunidades rurais devem apresentar determinadas características como simplicidade operacional e baixo custo uma vez que, normalmente, o próprio usuário é o responsável pela implantação e monitoramento do sistema. Sistemas de filtração em múltiplas etapas, filtração lenta e uso de coagulantes naturais são alguns dos tipos de tecnologias indicadas para esta população.

A filtração lenta em areia teve origem a partir da observação da percolação natural das águas através do solo. É considerada um processo que apresenta simplicidade operacional, capaz de remover sólidos, utilizado há décadas para o tratamento de água visando à potabilidade em comunidades rurais (Coelho \& Di Bernardo, 2012).

A Moringa oleifera é uma espécie originária do nordeste indiano (Gallão et al., 2006), cujas sementes contêm proteínas com alta massa molecular responsáveis pelo processo de coagulação (Ghebremichael et al., 2005) tornando possível a remoção de impurezas presentes na água por meio dos processos de sedimentação ou filtração.

Estudos realizados utilizando-se a Moringa oleifera aliada à filtração no tratamento de água evidenciam bons resultados (Babu \& Chaudhuri, 2005; Beltran-Heredia \& SánchezMartín, 2009; Franco et al., 2012). Após filtração direta Babu \& Chaudhuri (2005) verificaram valores de turbidez variando entre 0,3 e 1,1 UNT. Beltran-Heredia \& Sánchez-Martín (2009) notaram redução virtual de turbidez de $100 \%$ após filtração. Na filtração lenta Franco et al. (2012) constataram redução de turbidez de 99,0\%.

Babu \& Chaudhuri (2005) e Franco et al. (2012), que utilizaram o coagulante na forma de solução aquosa após mistura do pó com água destilada verificaram que a aplicação do mesmo resulta em rápido entupimento dos filtros devido ao incremento de matéria orgânica na água.

A presença de matéria orgânica já foi constatada até mesmo na água após o tratamento por Ndabigengesere \& Narasiah (1998); Okuda et al. (2001) e Ghebremichael et al. (2005). Poumaye et al. (2012) verificaram que a etapa de filtração é necessária para a remoção da matéria orgânica introduzida pelo coagulante.

$\mathrm{O}$ uso de sementes de Moringa oleifera confinado em sachês, já foi reportado por Pritchard et al. (2010). Os referidos autores afirmaram que, embora essa técnica tenha ocasionado redução significativa da turbidez na realização de ensaios de sedimentação, mais estudos são necessários para otimizar a aplicação do coagulante confinado em sachês.
Neste contexto, o estudo objetivou comparar o método convencional de utilização do coagulante à base de sementes de Moringa oleifera com o uso de sachês na redução de turbidez e cor aparente da água para consumo humano.

\section{MAterial e Métodos}

Este estudo foi realizado no Laboratório de Saneamento e no Laboratório de Hidráulica e Irrigação da Faculdade de Engenharia Agrícola da Universidade Estadual de Campinas (FEAGRI/UNICAMP), localizada nas coordenadas $22^{\circ} 49^{\prime \prime} 8.6^{\prime} \mathrm{S}$ e $47^{\circ} 3$ " 38.37’ W.

Após a realização das etapas de coagulação e flcoulação utilizando-se o coagulante à base de sementes de Moringa oleifera nas formas de sachê e suspensão aquosa, foram efetuados ensaios de filtração. Ensaios controle (sem adição de coagulante) também foram realizados. As sementes de Moringa oleifera utilizadas no estudo foram coletadas no Campo Experimental da FEAGRI/UNICAMP, secadas em estufa a $65^{\circ} \mathrm{C}$ por $24 \mathrm{~h}$ e armazenadas em estufa com controle de temperatura (aproximadamente $5^{\circ} \mathrm{C}$ ) até o momento de seu uso.

O material utilizado para confecção dos sachês (filtro de papel Mellita ${ }^{\circledR}$ ) e a massa de pó adicionada ao interior dos mesmos $(0,8 \mathrm{~g})$ foram definidos a partir de estudos realizados por Silva (2012). As sementes de Moringa oleifera foram descascadas manualmente e processadas em triturador manual com base em Arantes et al. (2012), utilizando pó, sem peneiramento (granulometria de 1,68 a 0,21 mm), na confecção dos sachês, conforme descrito por Pritchard et al. (2010). A Figura 1 representa o sachê com o pó e vedado com adesivo termoplástico.

Para o preparo do coagulante líquido adotou-se o método adaptado por Arantes (2012). Sementes de Moringa oleifera secadas previamente e armazenadas em temperatura e umidade controlada, foram descascadas manualmente, processadas em triturador manual e passadas em peneira com abertura de 0,84 $\mathrm{mm}$. Ao pó obtido adicionou-se água destilada e deionizada na concentração de $20 \mathrm{~g} \mathrm{~L}^{-1}$. Após a homogeneização do pó em água com uso de agitador magnético por $3 \mathrm{~min}$, a suspensão resultante foi passada por peneira de abertura de $0,125 \mathrm{~mm}$. Desta solução se utilizou a dosagem de $10 \mathrm{~mL} \mathrm{~L}^{-1}$, conforme recomendação de Silva (2012). Tal solução foi utilizada imediatamente após o preparo.

A turbidez da água a ser tratada foi obtida sinteticamente, procedimento já adotado por autores, como Ghebremichael

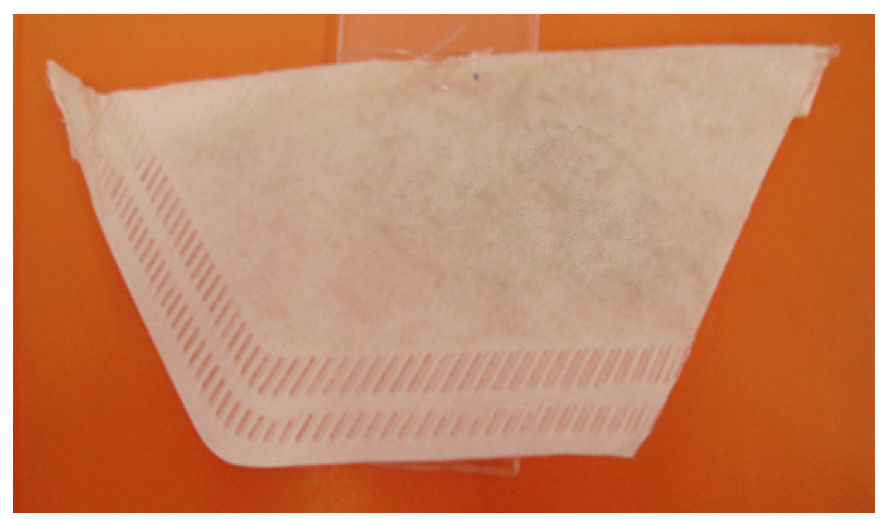

Figura 1. Sachê com o pó de sementes de Moringa oleifera 
et al. (2005), Paterniani et al. (2010) e Pritchard et al. (2010). Foram adicionadas $0,2 \mathrm{~g} \mathrm{~L}^{-1}$ de bentonita em água destilada e deionizada efetuando-se a agitação desta solução, pelo tempo de $30 \mathrm{~min}$. Esta mistura ficou em repouso durante 24 h; o sobrenadante foi coletado e utilizado como água bruta que apresentou turbidez de aproximadameente 60,0 UNT e partículas com tamanho inferior a $12 \mu \mathrm{m}$.

Após a adição da água bruta aos jarros do equipamento Jar-Test, os sachês contendo $0,8 \mathrm{~g}$ de pó foram fixados no seu interior iniciando-se a etapa de dispersão do coagulante em que agitação foi mantida por 35 min com gradiente de velocidade de $20 \mathrm{~s}^{-1}$ para favorecer a dispersão da proteína responsável pela coagulação, conforme descrito por Silva (2012).

Ao final da dispersão os sachês foram retirados do jarro para que ocorressem as etapas de coagulação pelo período de $30 \mathrm{~s}$. com gradiente de velocidade de $400 \mathrm{~s}^{-1}$, e floculação por $10 \mathrm{~min}$ a $20 \mathrm{~s}^{-1}$. Nos tratamentos com uso do coagulante líquido após a adição da dosagem de $10 \mathrm{~mL} \mathrm{~L}^{-1}$ a $20 \mathrm{~g} \mathrm{~L}^{-1}$, efetuaram-se as etapas de coagulação e floculação, sem a realização da etapa de dispersão; em seguida, a água foi direcionada do Jar-Test para o sistema de filtração. No bico coletor de cada jarro foi fixada uma mangueira de silicone e na outra extremidade de cada mangueira foi conectado um pequeno registro. Os registros provenientes dos seis jarros foram montados em série; um sétimo registro foi adicionado ao sistema e a partir deste foram efetuados o controle de vazão e o direcionamento

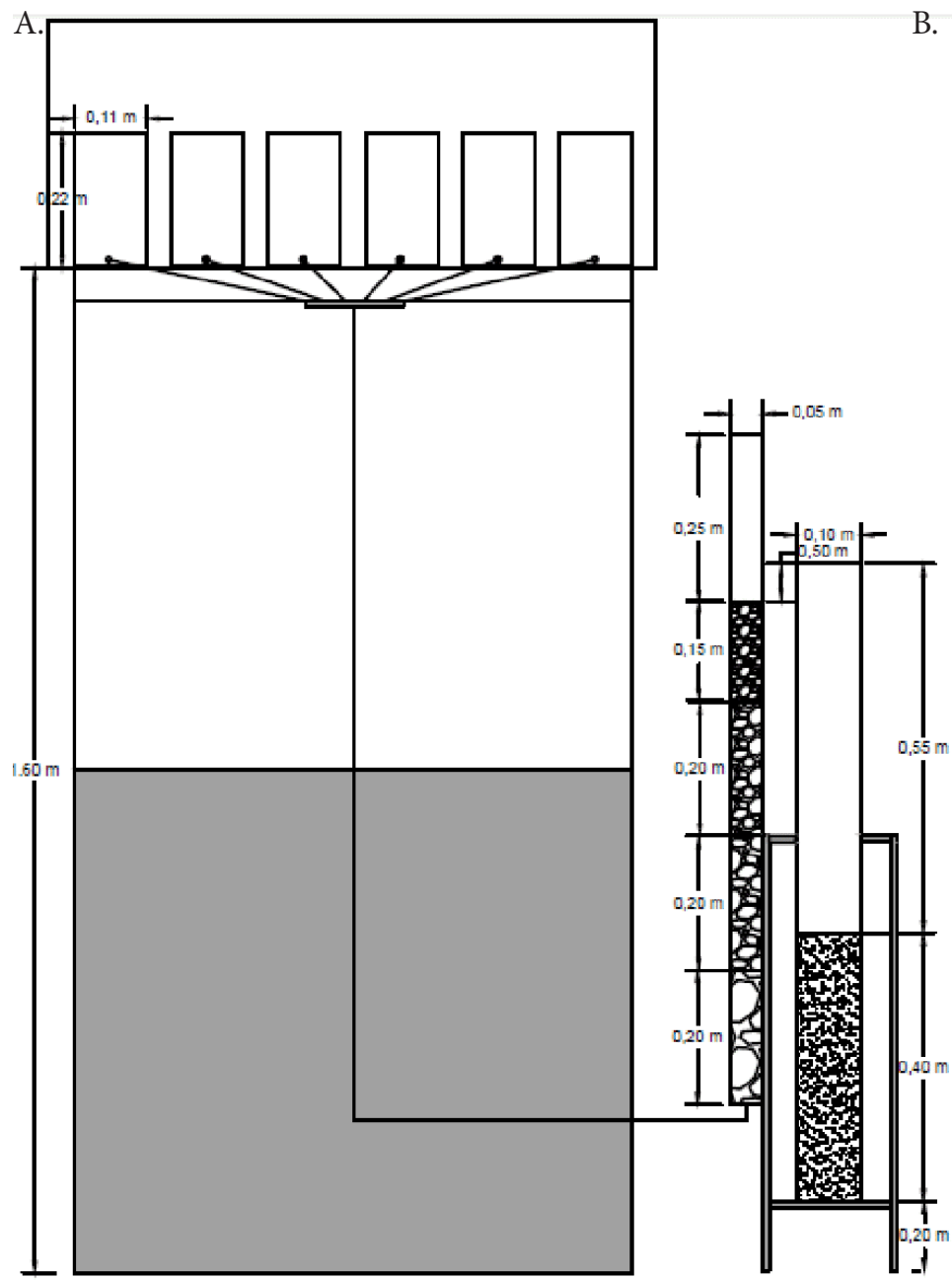

da água para o pre-filtro e posteriormente para o filtro lento, conforme ilustrado na Figura 2.

O pre-filtro ascendente de pedregulho foi construído em PVC com diâmetro de $0,05 \mathrm{~m}$, altura de $1,0 \mathrm{~m}$ e meio filtrante composto por quatro camadas de pedregulho três das quais com $0,20 \mathrm{~m}$ e granulometrias de 12,7 a 19,0; 6,4 a 12,7 e 3,2 a $6,4 \mathrm{~mm}$. A camada superior apresentou $0,15 \mathrm{~m}$ de altura e granulometria oscilando entre 1,68 e $3,2 \mathrm{~mm}$. A granulometria do pedregulho foi adotada com base em $\mathrm{Di}$ Bernardo (1999).

O filtro lento também foi construído em PVC com 0,10 $\mathrm{m}$ de diâmetro e $1 \mathrm{~m}$ de altura e meio filtrante constituído de uma camada de areia de construção civil peneirada com 0,40 $m$ de espessura e geotêxtil sintético nãotecido.

Seguindo recomendações de Ferraz \& Paterniani (2002) a areia de construção civil foi peneirada dentro da faixa granulométrica de 0,8 e $1,0 \mathrm{~mm}$. O tamanho efetivo dos grãos (D10) da areia utilizada neste estudo foi de $0,17 \mathrm{~mm}$ e o coeficiente de uniformidade (D60/D10) 3,5, valores esses de acordo com o determinado por Di Bernardo (1999).

No topo da camada de areia foram colocados geotêxtil sintético nãotecido com base em recomendações de Ferraz \& Paterniani (2002). Tratamentos foram efetuados variandose o tipo de nãotecido sintético presente no meio filtrante: 2 camadas de nãotecido com gramatura de $600 \mathrm{~g} \mathrm{~m}^{-2} \mathrm{e} 2$ camadas de nãotecido de $400 \mathrm{~g} \mathrm{~m}^{-2}$ no topo da camada de areia. Além

Figura 2. Instalação de bancada utilizada no estudo, apresentando um esquema (A) e uma ilustração do sistema em laboratório (B) 
dos tratamentos com uso de coagulantes, efetuou-se ensaio controle (sem adição do coagulante).

Com exceção dos ensaios controle, durante o período noturno a filtração foi suspensa devido à impossibilidade de dosagem dos coagulantes. O final dos ensaios consistiu na determinação da perda de carga decorrente da retenção de impurezas, quando se efetuavase a limpeza do filtro após cada uma das repetições dos tratamentos.

Em todos os tratamentos e ensaios controle se manteve, ao longo da filtração, agitação lenta (gradiente de velocidade de aproximadamente $10 \mathrm{~s}^{-1}$ ) para evitar a sedimentação. A Figura 3 representa os tratamentos realizados. Os ensaios com uso de sachê e coagulante líquido foram efetuados em triplicata. Os ensaios controle foram feitos em duplicata.

Amostras foram coletadas, diariamente, nos jarros após a dispersão da proteína ou adição do coagulante líquido e a cada $2 \mathrm{~h}$ na saída do pre-filtro e do filtro lento. Determinaram-se a turbidez, a cor aparente, a concentração de proteína, o pH e a temperatura. As análises de turbidez, cor aparente e $\mathrm{pH}$, foram feitas com base no Standard Methods (APHA/AWWA/ WEF, 2005). A concentração de proteína foi determinada pelo método de Lowry adaptado por Madrona et al. (2011).

Para os valores de turbidez e cor aparente realizou-se análise de variância. A hipótese de normalidade, testada com base nos testes Anderson-Darling, Kolmogorov-Sirmov e Shapiro-Wilk, foi rejeitada. Desta forma, efetuou-se análise de variância nãoparamétrica utilizando-se o teste de Kruskal-Wallis a nível de significância $5 \%(\mathrm{p} \leq 0,05)$. A análise de normalidade e o teste de Kruskal-Wallis foram efetuados no programa R ( Development Core Team, 2013).

\section{Resultados e Discussão}

Ao longo dos ensaios, a taxa média de filtração para o préfiltro variou entre 22,9 e $24,6 \mathrm{~m}^{3} \mathrm{~m}^{-2} \mathrm{~d}^{-1}$. No filtro lento e se considerando os seis tratamentos, foram verificados valores médios para a taxa de filtração de 5,3 a $5,6 \mathrm{~m}^{3} \mathrm{~m}^{-2} \mathrm{~d}^{-1}$. Os valores recomendados por Di Bernardo (1999) são taxa de filtração
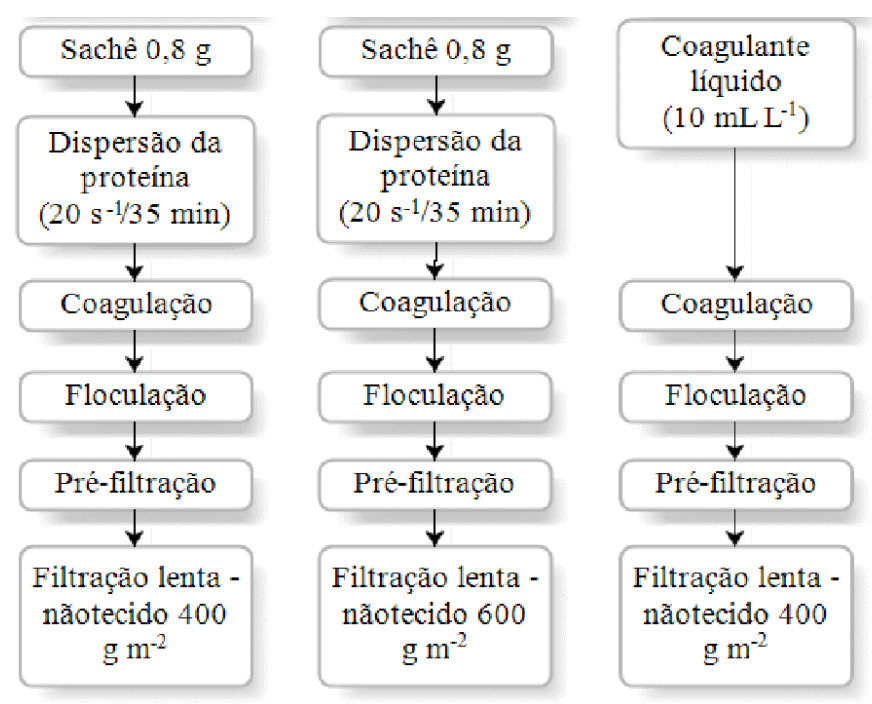

entre 12,0 e $36,0 \mathrm{~m}^{3} \mathrm{~m}^{-2} \mathrm{~d}^{-1}$ no pré-filtro e taxas de 3,0 a 6,0 $\mathrm{m}^{3} \mathrm{~m}^{-2} \mathrm{~d}^{-1}$ no filtro lento. A temperatura da água durante os ensaios permaneceu entre 18,4 a $23,4{ }^{\circ} \mathrm{C}$.

A Figura 4 representa os valores máximos, mínimos, medianos e quartis para a turbidez da água tratada, ao longo da filtração na saída do pré-filtro e do filtro lento, para os quatro tratamentos com uso de coagulante. Os tratamentos representados por letras iguais não diferem pelo teste de Kruskal-Wallis ( $\mathrm{p} \leq 0,05)$.

Constatou-se, para a água tratada pelo pré-filtro, que nos tratamentos com a utilização do coagulante líquido há tendência de valores menores de turbidez havendo diferença significativa entre os tratamentos coagulante líquido e sachê com base no teste de Kruskal-Wallis ( $\mathrm{p} \leq 0,05)$.

Para a água tratada pelo filtro lento, os valores de turbidez observados com o uso dos sachês são inferiores ao constatado com a aplicação do coagulante líquido, observando-se diferença significativa entre o uso de sachês e o coagulante líquido.

Tratamentos com a mesma forma de aplicação do coagulante (líquido e sachê) não apresentaram diferença significativa para a água tratada pelo pré-filtro nem no filtro lento. A utilização de meios filtrantes com diferentes gramaturas (400 e $600 \mathrm{~g} \mathrm{~m}^{-2}$ ) no filtro lento também não resultou em diferença significativa quando se considera cada forma de aplicação do coagulante (líquido ou sachê) isoladamente.

Poumaye et al. (2012) verificaram, em ensaios de filtração de água tratada anteriormente com Moringa oleífera, valores de turbidez final de 1,7 UNT. Neste estudo, embora tenham sido observados valores abaixo de 2,0 UNT ao longo da filtração lenta, valores superiores a este predominaram. De acordo com Portaria no 2914/2011 do Ministério da Saúde (Brasil, 2011), no tratamento por filtração lenta, o valor máximo permitido para turbidez é 1,0 UNT em 95\% das amostras. Os dados desta pesquisa demonstram que tal condição não é atendida.

Nos tratamentos controle constatou-se que sem a adição de coagulante a redução de turbidez é baixa ou até mesmo inexistente. Para a água tratada pelo pré-filtro foram constatados valores de turbidez na faixa de 60,0 UNT, o mesmo
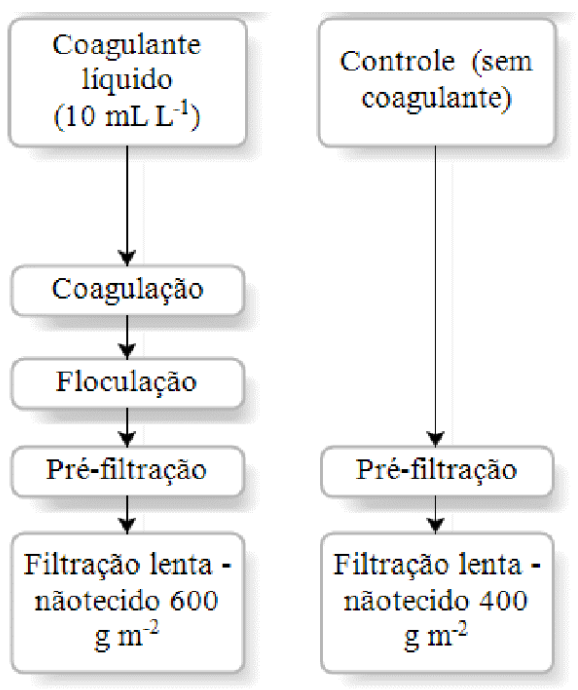

\section{Controle (sem coagulante)}

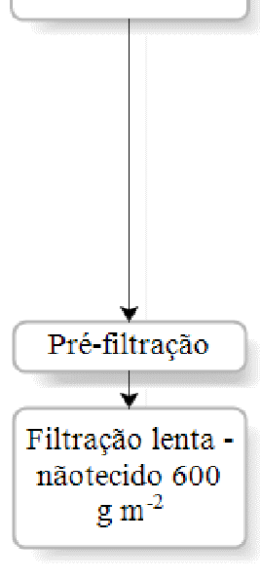

Coagulação: Gradiente de $400 \mathrm{~s}^{-1}$ por 30 segundos Floculação: Gradiente de $20 \mathrm{~s}^{-1}$ por 10 minutos

Figura 3. Tratamentos efetuados em função das dosagens e etapas adotadas no tratamento da água 

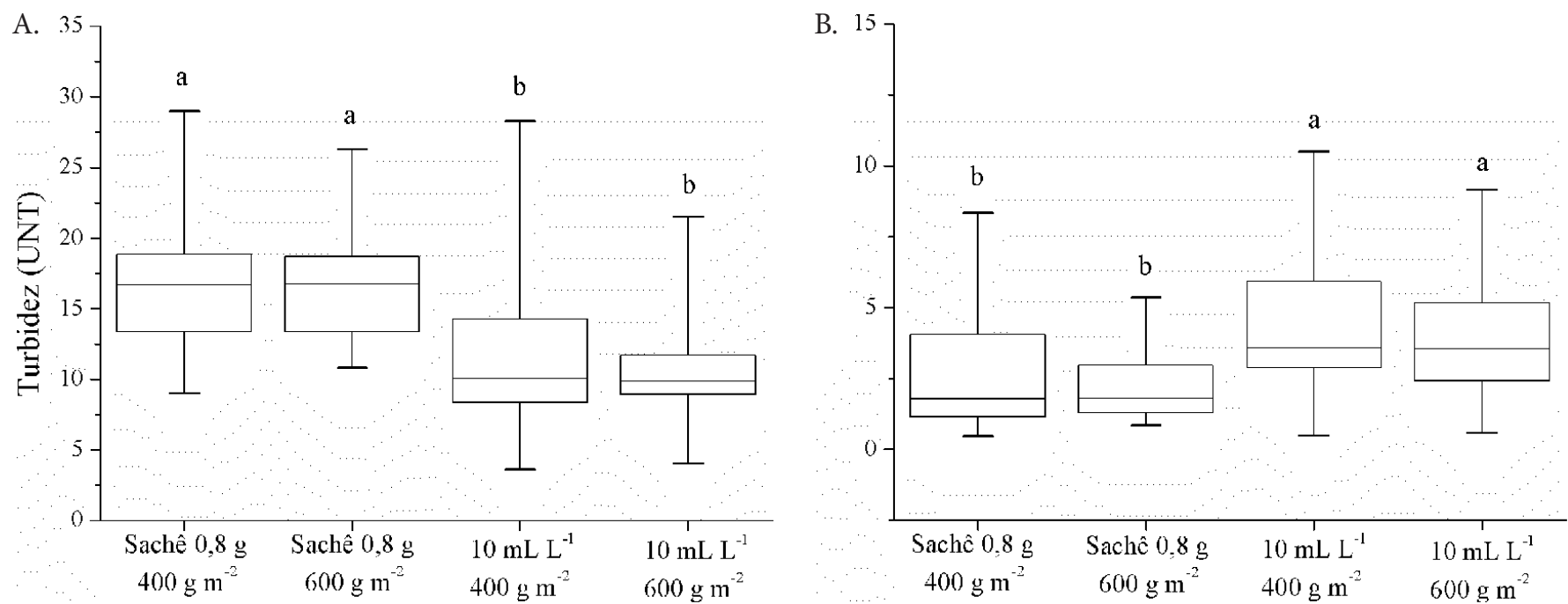

Figura 4. Valores máximos, mínimos, medianos e quartis da turbidez da água filtrada no pré-filtro (A) e no filtro lento (B) para os tratamentos com uso de sachê e coagulante líquido

verificado para a água bruta. No filtro lento foram verificados valores entre 40,0 e 60,0 UNT.

A eficiência de redução para turbidez é apresentada na Tabela 1 na qual constam valores médios, máximo e mínimo, ao longo da filtração para cada um dos tratamentos realizados com uso de coagulante. A eficiência do pré-filtro foi calculada com base na turbidez da água bruta e da água tratada nesta unidade. No filtro lento foram utilizados valores de turbidez da água tratda pelo pré-filtro e do filtro lento; já a eficiência global se refere ao cálculo considerando-se a turbidez da água bruta e da água tratada pelo filtro lento.

Verificou-se, para o pré-filtro, que maior redução de turbidez com o uso do coagulante líquido obtendo-se percentuais médios de redução de turbidez iguais a 82 e $83 \%$ nesses tratamentos em que, com o uso dos sachês, os percentuais médios foram 75 e $72 \%$.

No filtro lento ocorreu o contrário, notando-se percentuais médios superiores (82 e 86\%) com o uso dos sachês. Para o coagulante líquido os valores médios constatados foram $58 \mathrm{e}$ $63 \%$. Considerando a eficiência global tanto dos tratamentos com uso de coagulante líquido como dos sachês, evidenciaramse elevados percentuais de redução da turbidez.

Beltrán-Heredia \& Sánchez-Mártin (2009) verificaram, utilizando a Moringa oleifera em ensaios de filtração lenta no tratamento de água superficial, redução virtual de 100,0\% para turbidez. Franco et al. (2012) demonstraram, utilizando um sistema de filtração em múltiplas etapas, que a aplicação de coagulante líquido à base de sementes de Moringa oleifera resultou, no filtro lento, em redução de $99,0 \%$ da turbidez. Verificou-se, quando se considera redução global de turbidez, que os resultados obtidos estão de acordo com a literatura
(Beltrán-Heredia \& Sánchez-Mártin, 2009; Franco et al. (2012).

Pritchard et al. (2010) obtiveram, utilizando sementes de Moringa oleifera confinadas em sachês no tratamento de água com turbidez de 146 UNT, redução de turbidez de aproximadamente $85 \%$ em ensaios de sedimentação, percentual semelhante aos valores médios (Tabela 1) verificados para a água tratada pelo filtro lento neste trabalho.

A aplicação do coagulante tanto na forma de sachê como na solução aquosa, implicou em aumento da turbidez da água bruta porém com o uso dos sachês este aumento foi em menor proporção e mesmo nessas condições, nos ensaios com uso de sachê, o entupimento do filtro ocorreu mais rapidamente, situação passível de ser justificada pela menor eficiência do pré-filtro quando se utilizou o sachê, o que sobrecarregou o filtro lento. Recomenda-se, portanto, a adoção de mais unidades de filtração antecedendo o filtro lento ou a adoção de pré-tratamentos que garantam melhor qualidade da água a ser tratada no filtro lento, impactando menos esta unidade.

Os valores máximos, mínimos, medianos e quartis observados para a variável cor aparente estão representados na Figura 5. Os tratamentos acompanhados de letras iguais não diferem significativamente pelo teste de Kruskal-Wallis $(\mathrm{p} \leq 0,05)$.

O comportamento para cor aparente foi análogo ao observado para turbidez, com tendência de valores mais elevados para tratamentos com uso de sachê no pré-filtro (Figura $5 \mathrm{~A}$ ) e valores menores para os mesmos tratamentos para a água tratada pelo filtro lento. A comparação entre os tratamentos com uso coagulante líquido e sachê por meio do teste de Kruskal-Wallis $(\mathrm{p} \leq 0,05)$ apontou que existem diferenças significativas entre

Tabela 1. Valores médios, máximo e mínimo de redução de turbidez (\%) para os quatro tratamentos com uso de coagulante

\begin{tabular}{|c|c|c|c|c|c|c|c|c|c|c|c|c|}
\hline & \multicolumn{12}{|c|}{ Meio filtrante } \\
\hline & \multicolumn{6}{|c|}{ Sachê $0,8 \mathrm{~g}$} & \multicolumn{6}{|c|}{ Coagulante líquido } \\
\hline & \multicolumn{3}{|c|}{$400 \mathrm{~g} \mathrm{~m}^{-2}$} & \multicolumn{3}{|c|}{$600 \mathrm{~g} \mathrm{~m}^{-2}$} & \multicolumn{3}{|c|}{$400 \mathrm{~g} \mathrm{~m}^{-2}$} & \multicolumn{3}{|c|}{$600 \mathrm{~g} \mathrm{~m}^{-2}$} \\
\hline & Pré-filtro & Filtro lento & Global & Pré-filtro & Filtro lento & Global & Pré-filtro & Filtro lento & Global & Pré-filtro & Filtro lento & Global \\
\hline Média & 75 & 82 & 96 & 72 & 86 & 96 & 82 & 58 & 93 & 83 & 63 & 95 \\
\hline Máx. & 85 & 95 & 99 & 80 & 95 & 98 & 94 & 81 & 96 & 91 & 89 & 98 \\
\hline Mín. & 65 & 50 & 88 & 64 & 68 & 93 & 71 & 10 & 86 & 71 & 22 & 91 \\
\hline
\end{tabular}



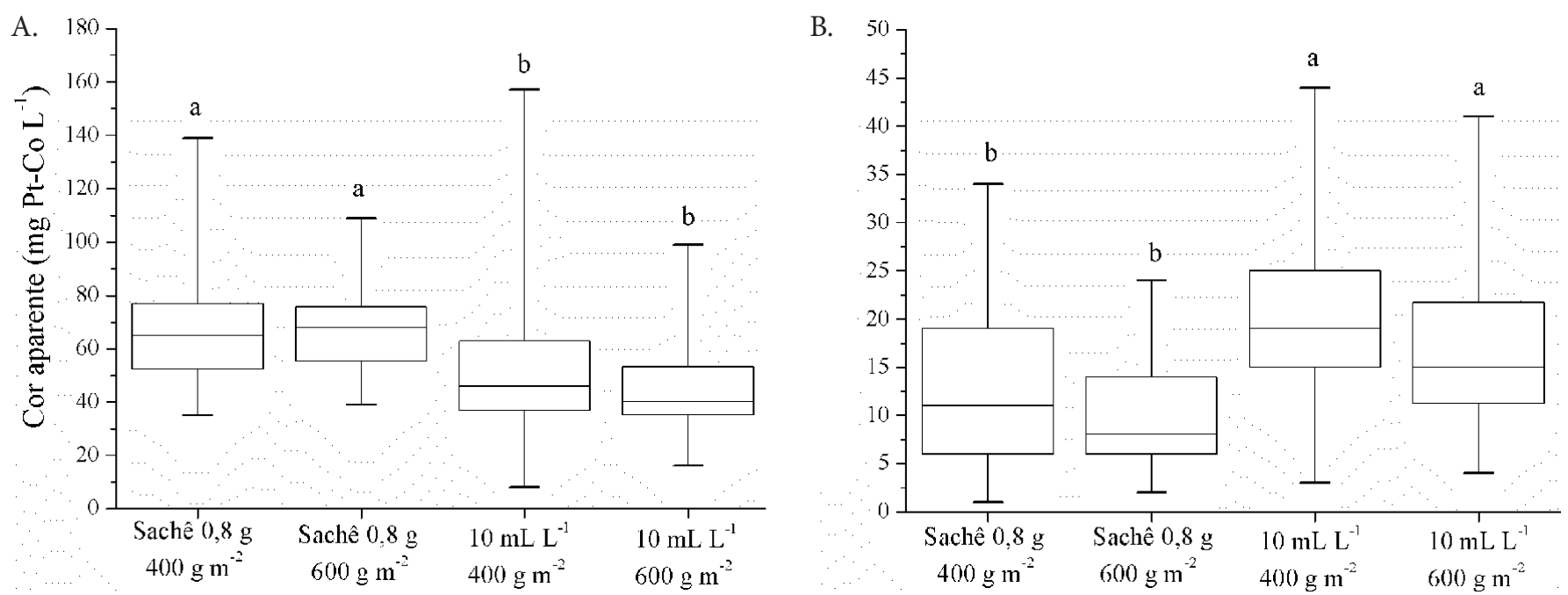

Figura 5. Valores máximos, mínimos, medianos e quartis da cor aparente da água filtrada no pré-filtro (A) e no filtro lento (B) para os tratamentos com uso de sachê e coagulante líquido

os mesmos. Para os ensaios controle a redução de cor aparente também foi baixa ou inexistente. O valor máximo permitido para cor aparente, de acordo com a Portaria no 2914/2011 do Ministério da Saúde (Brasil, 2011) é de 15 mg Pt-Co L ${ }^{-1}$, e conforme Figra 5B, o tratamento que mais se aproximou de tais condições foi com o uso do sachê de $0,8 \mathrm{~g}$ e meio filtrante com gramatura de $600 \mathrm{~g} \mathrm{~m}^{-2}$.

Na Tabela 2 constam os percentuais médios, máximo e mínimo para redução de cor aparente verificados ao longo da filtração.

No pré-filtro, para tratamentos com uso de sachês, foram observados percentuais médios de redução de cor aparente de 77 e $79 \%$. Para o coagulante líquido tais valores foram 84 e $86 \%$, No filtro lento percentuais médios mais elevados (81 e $84 \%$ ) foram verificados com o uso dos sachês; no entanto, para os quatro tratamentos verificou-se redução global superior a 93\%. Tais resultados corroboram o observado por Franco et al. (2010), que verificaram redução de cor aparente na faixa de 89 a $91 \%$.

A água bruta utilizada nos ensaios apresentou concentração de proteína abaixo de $4,3 \mathrm{mg} \mathrm{L}^{-1}$, entretanto, em alguns momentos esse composto não foi detectado. Após adição dos coagulantes verificou-se concentração média de proteína com o uso dos sachês igual a $30,8 \pm 1,6$ e $37,5 \pm 3,3 \mathrm{mg} \mathrm{L}^{-1}$ para o coagulante líquido.

Após a filtração houve redução na concentração de proteína. Na água tratada do pré-filtro e do filtro lento ao longo dos ensaios detectaram-se concentrações máximas de proteína iguais 15,7 e $6,4 \mathrm{mg} \mathrm{L}^{-1}$, respectivamente. Em determinados momentos não se detectou presença de proteína na água tratada das duas unidades de filtração.
Rolim et al. (2011) verificaram que a adição do extrato de Moringa oleifera na concentração correspondente a 200 mg pó $\mathrm{L}^{-1}$ de água a ser tratada, não apresenta efeito genotóxico de vez que não foram observadas mutações genéticas em cepas de Salmonella typhimurium. Neste estudo a dosagem de 10 $\mathrm{mL} \mathrm{L}^{-1}$ a $2 \%$ seria o equivalente a $200 \mathrm{mg} \mathrm{L}^{-1}$, considerada uma dosagem segura, de acordo com os dados obtidos por Rolim et al. (2011). Os referidos autores não relacionaram a concentração de proteína ao efeito genotóxico não sendo possível avaliar se o uso dos sachês poderia originar algum dano à saúde humana.

Recomenda-se, desta forma, a realização de estudos de genotoxicidade considerando-se a concentração de proteína e não apenas a massa de Moringa oleifera adicionada à água a ser tratada. Outro fator a ser observado é que os testes realizados por Rolim et al. (2011) não consideram que após o tratamento ocorre redução de proteína e de outros compostos provenientes das sementes de Moringa oleifera. Os dados deste estudo demonstram que, ao final do tratamento, a concentração de proteína foi reduzida em pelo menos $78,0 \%$; em certas situações a presença deste composto não foi detectada.

Para a água bruta foram observados valores de $\mathrm{pH}$ na faixa de 7,1 a-8,6. Após o tratamento com uso de coagulantes os valores observados variaram entre 6,1 e 8,6. Ndabigengesere \& Narasiah (1998) e Valverde et al. (2013) constataram que o uso do coagulante à base de Moringa oleifera não ocasiona alterações no $\mathrm{pH}$ da água após o tratamento.

Neste estudo foram evidenciados, embora em determinados momentos, valores abaixo de 7,0 para o pH; essas alterações não tornariam a água imprópria para o consumo humano pois, de acordo com a Portaria no 2914/2011 do Ministério da

Tabela 2. Valores médios, máximo e mínimo de redução de cor aparente (\%) para os quatro tratamentos com uso de coagulante

\begin{tabular}{|c|c|c|c|c|c|c|c|c|c|c|c|c|}
\hline & \multicolumn{12}{|c|}{ Meio filtrante } \\
\hline & \multicolumn{6}{|c|}{ Sachê $0,8 \mathrm{~g}$} & \multicolumn{6}{|c|}{ Coagulante líquido } \\
\hline & \multicolumn{3}{|c|}{$400 \mathrm{~g} \mathrm{~m}^{-2}$} & \multicolumn{3}{|c|}{$600 \mathrm{~g} \mathrm{~m}^{-2}$} & \multicolumn{3}{|c|}{$400 \mathrm{~g} \mathrm{~m}^{-2}$} & \multicolumn{3}{|c|}{$600 \mathrm{~g} \mathrm{~m}^{-2}$} \\
\hline & Pré-filtro & Filtro lento & Global & Pré-filtro & Filtro lento & Global & Pré-filtro & Filtro lento & Global & Pré-filtro & Filtro lento & Global \\
\hline Média & 79 & 81 & 96 & 77 & 84 & 96 & 85 & 52 & 93 & 86 & 58 & 95 \\
\hline Máx. & 89 & 94 & 99 & 84 & 94 & 98 & 92 & 80 & 97 & 93 & 89 & 97 \\
\hline Mín. & 71 & 54 & 90 & 69 & 69 & 94 & 73 & 10 & 86 & 73 & 23 & 91 \\
\hline
\end{tabular}


Saúde (Brasil, 2011) o pH da água no sistema de distribuição deve ser mantido entre 6,0 e 9,5.

\section{Conclusões}

1. O uso do sachê mostrou-se menos eficiente na unidade de pré-filtração. Em contrapartida, no filtro lento e considerando todo o sistema de filtração o sachê se mostrou mais eficiente que o coagulante líquido.

2. A diferença entre tratamentos com uso de sachê e coagulante líquido foi significativa, tanto para a água tratada do pré-filtro como do filtro lento.

3. Nos ensaios com uso de sachê o entupimento do filtro lento ocorreu em menor tempo devido à menor eficiência do pré-filtro em tais tratamentos.

4. O coagulante na forma de sachê apresentou potencialidade de uso na filtração quando se considerou não só a redução de turbidez mas também a cor aparente.

\section{Agradecimentos}

À FAPESP (processo: 2010/09395-0) pela concessão de bolsa de doutorado.

\section{Literatura Citada}

APHA/AWWA/WEF - American Public Health Association/ American Water Works Association/Water Environment Federation. Standard Methods for the examination of water and wastewater. 21.ed. Washington: American Public Health Association/American Water Works Association/Water Environment Federation, 2005. 1600p.

Arantes, C. C.; Ribeiro, T. A. P.; Paterniani, J. E. S. Processamento de sementes de Moringa oleifera utilizando-se diferentes equipamentos para obtenção de solução coagulante. Revista Brasileira de Engenharia Agrícola e Ambiental, v.16, p.661-666, 2012. http://dx.doi.org/10.1590/S1415-43662012000600011

Babu, R.; Chaudhuri, M. Home water treatment by direct filtration with natural coagulant. Journal of Water and Health, v.3, p.2730, 2005.

Beltrán-Heredia, J.; Sánchez-Martín, J. Improvement of water treatment pilot plant with Moringa oleifera extract as flocculant agent. Environmental Technology, v.30, p.525-534, 2009. http:// dx.doi.org/10.1080/09593330902831176

Brasil. Ministério da Saúde. Portaria n.2914, de 12 de Dezembro de 2011. Dispõe sobre os procedimentos de controle e de vigilância da qualidade da água para consumo humano e seu padrão de potabilidade. 2011. <http://www.saude.gov.br>. 2 Jan. 2014.

Coelho, E. R. C.; Di Bernardo, L. Remoção de atrazina e metabólitos pela filtração lenta com leito de areia e carvão ativado granular. Engenharia Sanitária e Ambiental, v.17, p.269-276, 2012. http:// dx.doi.org/10.1590/S1413-41522012000300003

Di Bernardo, L. (coord.). Tratamento de águas de abastecimento por filtração em múltiplas etapas. 1.ed. Rio de Janeiro: ABES, 1999. 114p.

Ferraz, F. C.; Paterniani, J. E. S. Redução da espessura da camada suporte através da substituição por mantas sintéticas não tecidas na filtração lenta de água de abastecimento. Revista Engenharia Sanitária e Ambiental, v.7, p.8-15, 2002.
Franco, M; Silva, G. K; Paterniani, J. E. S. Water treatment by multistage filtration system with natural coagulant from Moringa oleifera seeds. Engenharia Agrícola, v.32, p.989-997, 2012. http:// dx.doi.org/10.1590/S0100-69162012000500018

Gallão, M. I.; Damasceno, L. F.; Brito, E. S. Avaliação química e estrutural da semente de Moringa. Revista Ciência Agronômica, v.37, p.106-109, 2006.

Ghebremichael, K. A.; Gunaratn, K. R.; Henriksson, H.; Brumer, H.; Dalhamman, G. A simple purification and activity assay of the coagulant protein from Moringa oleifera seed. Water Research, v.39, p.2338-2344, 2005. http://dx.doi.org/10.1016/j.watres.2005.04.012

IBGE - Instituto Brasileiro de Geografia e Estatística. Sinopse do censo demográfico 2010.d<http://www.ibge.gov.br/home/estatistica/ populacao/censo2010/sinopse/default_sinopse.shtm>.13 Mar. 2012.

Madrona, G. S.; Bergamasco, R.; Seolin, V. J.; Klen, M. R. F. The potential of different saline solution on the extraction of the Moringa oleifera seed's active component for water treatment. International Journal of Chemical Reactor Engineering, v.9, p. 1542-6580, 2011. <http://www.degruyter.com/view/j/ijcre. 2011.9.issue-1/1542-6580.2511/1542-6580.2511.xml>. 16 Mar. 2014.

Ndabigengesere, A.; Narasiah, K. S. Quality of water treated by coagulation using Moringa oleifera seeds. Water Research, v.32, p.781-791, 1998. http://dx.doi.org/10.1016/S0043-1354(97)00295-9

Nascimento, N, O.; Heller, L. Ciência, tecnologia e inovação na interface entre as áreas de recursos hídricos e saneamento. Revista Engenharia Sanitária e Ambiental, v.10, p.36-48, 2005.

Okuda, T.; Baes, A. U.; Nishijima, W.; Okada, M. Isolation and characterization of coagulant extracted from Moringa oleifera seed by salt solution. Water Research, v.35, p.405-410, 2001. http:// dx.doi.org/10.1016/S0043-1354(00)00290-6

Paterniani, J. E. S.; Ribeiro, T. A. P.; Mantovani, M. C.; Sant'anna, M. R. Water treatment by sedimentation and slow fabric filtration using Moringa oleifera seeds. African Journal of Agricultural Research, v.5, p.1256-1263, 2010.

Poumaye, N.; Mabingui, J.; Lutgen, P.; Bigan, M. Contribution to the clarification of surface water from the Moringa oleifera: Case M'Poko River to Bangui, Central African Republic. Chemical Engeneering Research and Design. v.90, p.2346-2352, 2012.http:// dx.doi.org/10.1016/j.cherd.2012.05.017

Pritchard, M.; Craven, T.; Mkandawire, T.; Edmondson, A. S.; O’neill, J. G. A comparison between Moringa oleifera and chemical coagulants in the purification of drinking water - An alternative sustainable solution for developing countries. Physics and Chemistry of the Earth, v.35, p.798-805, 2010. http://dx.doi.org/10.1016/j.pce.2010.07.014

R Development Core Team. R: A language and environment for statistical computing. R Foundation for Statistical Computing, Vienna, 2011. <http://www.R-project.org/>. 10 Jul. 2013.

Rolim L. A. D. M. M.; Macêdo, M. F. S.; Sisenando, H. A.; Napoleão, T. H.; Felzenszwalb, I.; Aiub, C. A. F.; Coelho, L. C. B. B.; Medeiros, S. R. B.; Paiva, P. M. G. Genotoxicity evaluation of Moringa oleifera seed extract and lectin. Journal of Food Science, v.76, p.53-58, 2011. http://dx.doi.org/10.1111/j.1750-3841.2010.01990.x

Silva, G. K. Método alternativo para aplicação do coagulante natural Moringa oleifera no tratamento de água. Campinas: UNICAMP, 2012. 116p. Dissertação Mestrado

Valverde, K. C.; Moraes, L. C. K.; Bongiovani, F. P. C.; Bergamasco, R. Coagulation diagram using the Moringa oleifera Lam and the aluminium sulfate, aiming the removal of color and turbidity of water. Acta Scientarium. Technology, v.5, p.485-489, 2013. 